\title{
Necrotizing Sialometaplasia of the Hard Palate: A Case Report Observed at the University Teaching Hospital of Yaounde
}

\author{
Bengondo Messanga $C^{1}$, Nokam Abena $M^{1}$, Ntep Ntep $D^{1, *}$, Kenna $E^{1}$, Mendouga Mengne $C^{2}$ \\ ${ }^{1}$ Odontostomatology and Maxillofacial Surgery Department of the Yaounde University Teaching and Hospital Center \\ ${ }^{2}$ Pasteur Center of Yaoundé \\ *Corresponding author: ntep.david@yahoo.com
}

\begin{abstract}
Necrotising sialometaplasia is a rare inflammatory pathology of accessory salivary glands. It occurs exceptionally on the other main salivary glands. The aetiology remains to be determined. We report the case of a 37year-old patient who came to consult for a wound and oral pain that had been evolving for 4 months. Exobuccal examination showed nothing peculiar. The intraoral examination showed an ulceration of the palatal mucosa, nonindurated, elevated, with a yellow background. Despite these signs and the absence of a history of alcohol and tobacco consumption, bleeding and lymphadenopathy, we evoked the diagnosis squamous cell carcinoma of palate. An excision biopsy was performed to confirm the diagnosis of necrotising sialometaplasia. The postoperative course was simple. In front of a palatal ulcer with raised mucosa, not indurated, not bleeding, with a yellowish background, it is necessary to think of a sialometaplasia.
\end{abstract}

Keywords: necrotising sialometaplasia, squamous cell carcinoma, neoplastic ulceration

Cite This Article: Bengondo Messanga C, Nokam Abena M, Ntep Ntep D, Kenna E, and Mendouga Mengne C, "Necrotizing Sialometaplasia of the Hard Palate: A Case Report Observed at the University Teaching Hospital of Yaounde." International Journal of Dental Sciences and Research, vol. 6, no. 1 (2018): 22-24. doi: 10.12691/ijdsr-6-1-5.

\section{Introduction}

Necrotising sialometaplasia, described for the first time by Abrams in 1973 [1], is a rare inflammatory pathology of accessory salivary glands. Its aetiology is poorly understood aetiology $[2,3]$. Its clinical presentations can simulate malignancy [4], although it is a benign pathology. The knowledge of the clinical and histological criteria in favour of the benign character is essential for proper diagnosis. Our aim was to report a case of palatal necrotising sialometaplasia, observed at the University Teaching Hospital in Yaounde (Cameroon).

\section{Case Presentation}

In May 2017, a 37-year-old man was referred to the odontostomatology and maxillofacial surgery department of the university teaching hospital of Yaounde, for the management of an oral lesion. Patient described onset of lesion as a palatine swelling evolving over four months. The swelling increased in volume and later became ulcerated and painful. Pricking, itches and pain of moderate intensity irradiating to the ipsilateral ear were noticed, and these prompted the patient to come for consultation.

The history of the patient was unremarkable as well as the rest of the physical exam. Nevertheless, patient reported regular consumption of hot meals.

Physical examination revealed a non-pyretic patient. An ulcerated erythematous unilateral swelling on the posterior hemi palate at the level of the second and third molars was seen. The swelling was cylindrical on the hard palate with no extension to the mid palatal line. Lesion was a deep crateriform ulcer of $2 \mathrm{~cm}$ long and $1 \mathrm{~cm}$ wide with net borders. The underlying fibrin background had persisting necrotic debris as seen in (Figure 1). The base of the lesion was supple on palpation.

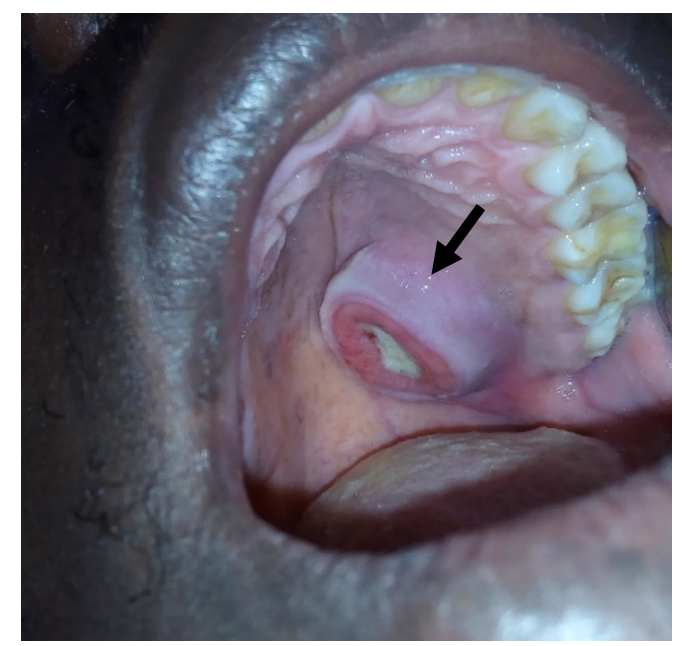

Figure 1. Clinical feature of necrotising sialometaplasia with central ulcer 


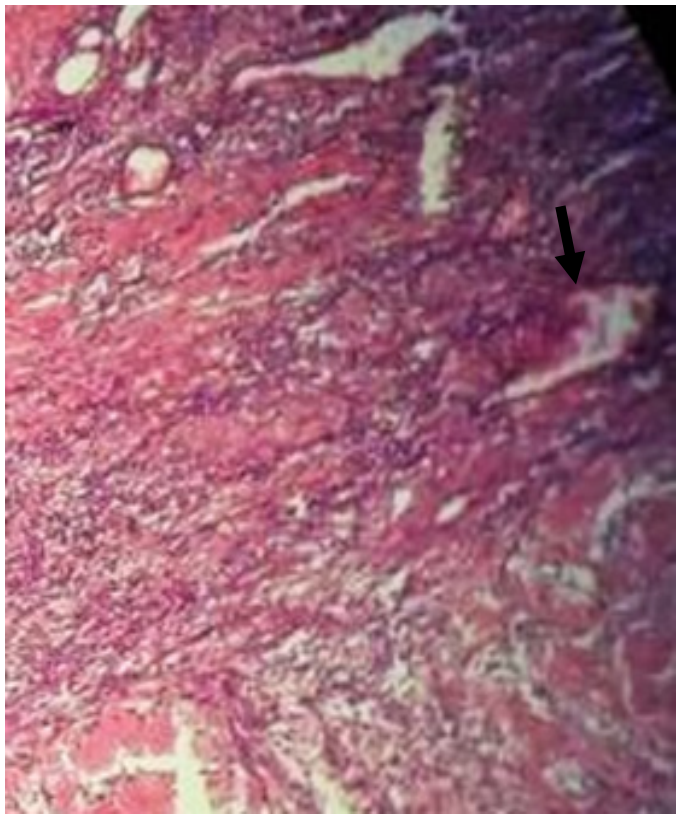

Figure 2. Histopathological features: Preservation of lobular architecture, atrophic acini, squamous metaplasia and inflammatory infiltrate

Suggested differentials were evoked: squamous cell carcinoma, necrotising sialometaplasia and oral gummatous syphilis. Excision biopsy was carried out and the sample was prepared for histopahtolgic analysis. Histology revealed an ulcerated malpighian mucosa. Subjacent salivary glands were undergoing extensive liquefaction necrosis, some acini presented epidermoid metaplasia, the presence of an inflammatory infiltrate, the preservation of the lobular appearance and the absence of signs of malignancy. The histologic aspect strongly evokes necrotizing sialometaplasia (Figure 2) Nontreponemal serology screening (VDRL: Venereal Disease Research Laboratory) and treponemal specific test (TPHA: Treponema Pallidum Hemagglutinations Assay) were negative. The HIV serology was also negative.

Full mouth scaling was done prior to the excision. Oral povidone iodine antiseptic, and antibiotics (amoxicillin) for 7 days were used for the management of the wound after biopsy. Healing was good and evolved over three weeks as seen in (Figure 3). Three months later, ad integrum restored mucosa was observed, with a persisting erythema, on the site of the excised lesion (Figure 4).

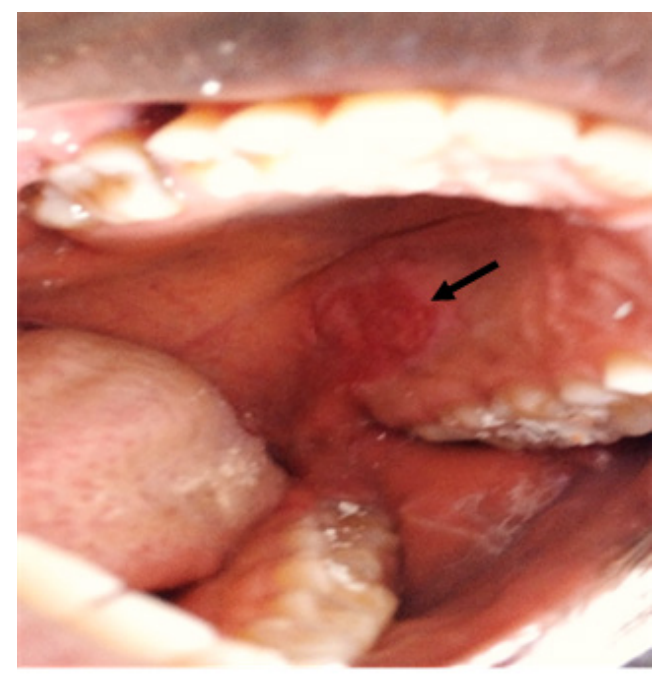

Figure 3. The mucosa, 3 weeks into wound healing after excision

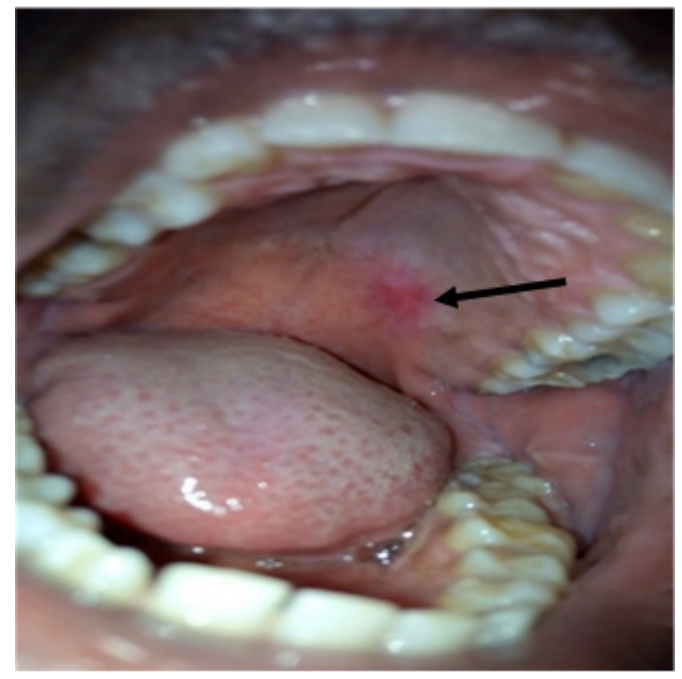

Figure 4. The mucosa 3 months after excision

\section{Discussion}

Sialometaplasia is a rare benign pathology. It represents less than $1 \%$ of oral lesions that have undergone biopsy and concerns a wide age range (1.5 to 83 years) [5]. The case here so reported is found within this range.

This is the first case encountered in several decades. Seventy nine per cent of this condition affects the palate [6], concurred by the reported case. In this case, the lesion corresponding to necrotizing sialometaplasia did not cross the midline of the palate. The median palatal raphe serves as limit that is respected by benign necrotizing sialometaplasia, in contrast to malignant neoplasia [7]. This element may already give a clue in favour of necrotising sialometaplasia.

The lesion presents as a swollen mass, tender on palpation, evolving within a few days into a centralised crateriform ulcer $[1,7]$. The lesion is a palatine mucosa ulcer with a white background, covered with necrotic debris and surrounded by an erythematous or whitish halo $[2,7]$. On first inspection, this lesion could mimic malignant lesions, as was the case in our case description.

Its aetiology and pathogenesis are subject to several controversies. Several theories have been proposed: literature describes vascular affections responsible for local ischaemia, followed by infarction [7,9]. According to this theory, first put forth by Abrams, any agent capable of causing a local tumour could cause local ischaemia responsible for the necrosis of the glandular elements [1]. In our case report, the probable insult reported by the patient is hot feeding.

The differential diagnosis at the initial stage is an odontogenic palatine abscess or minor salivary gland tumour (pleomorphic adenoma) [6]. At the ulcer stage, one could think of squamous cell carcinoma, supported by bleeding sanious background, budding, and indurated base, extending beyond the median raphe. Once could also suspect a major aphthae (Sutton disease), an ulcer of infectious origin (tuberculosis, syphilis, or systemic mycosis), agranulocytosis, non-Hodgkin lymphoma or a sarcoma $[7,9]$.

According to Kaplan and $a l$, necrotising sialometaplasia is marked by five traits: lobular infarction, epidermoid metaplasia affecting both the mucous acini and the ducts, persistence of ghost nuclei, presence of granulation tissue 
and inflammatory infiltrate; conserved lobular architecture despite inflammatory changes and metaplasia on the glands [9]. In this case, four aspects were found.

Generally, the certainty of diagnosis of sialometaplasia usually occurs at later stages of the progression of the disease (necrosis, or ulceration) as in this case [10]. Its management will be based on the stage of the condition. Initially, steroids would help prevent evolution to necrosis, but its relevance is still disputed. At necrosis, one can perform exeresis [11]. In our observation the lesion was not extensive, permitting us to carry out exeresis, added to the fact that the lesion evolved for over four months with no recovery. Analgesics and oral hygiene measures would complete the treatment. In the case reported, wound healing took a short period of 3 months, secondary to excision.

\section{Conclusion}

Necrotising sialometaplasia is a rare glandular lesion. It presents as an atypical ulcer simulating a neoplasm, without actually possessing its characteristics. In the presence of a palatine ulcer, therefore: if bleeding, a sanious background, a budding, and indurated base, and an extension beyond the median raphe can be eliminated, it is necessary to think of necrotizing sialometaplasia. It will be treated surgically at the stage of necrosis, with no post-operative complications.

\section{Conflicts of Interest: None .}

\section{References}

[1] Abrams AM, Melrose RJ, Howell FV. Necrotizing sialometaplasia. A disease simulating malignancy. Cancer. 1973; 32(1): 130-135.

[2] Damardji AR. Sialométaplasie nécrosante : présentation de 9 cas. Thèse de chirurgie dentaire. Université de Génève; 2011.

[3] Prabhakaran VC, Flora RS, Kendall C. Pressure-induced necrotizing sialometaplasia of the parotid gland. Histopathology. 2006; 48(4): 464-465.

[4] Boisnic S, Agbo S, Biaggi A, Pascal F, Szpirglas H, Frances C. La sialométaplasie nécrosante du palais : trois observations. Annales de dermatologie et de vénéréologie. Masson ; 1992. p. 922-924.

[5] Carlson DL. Necrotizing Sialometaplasia: A Practical Approach to the Diagnosis. Arch Pathol Lab Med. 2009 ;133(5):692-8.

[6] Aubies-Trouilh S, Fricain J-C. La sialométaplasie nécrosante : revue systématique de la littérature. Médecine Buccale Chir Buccale. $2012 ; 18(4): 347-359$.

[7] Constantin Stühmer, Harald Essig, Henning Feist, Kai-Hendrik Bormann, Nils-Claudius Gellrich, Martin Rücker. La sialométaplasie nécrosante : diagnostic d'une affection rare. Rev Mens Suisse Odontostomatol. $2008 ; 118: 637$.

[8] Belghith A, Njah H, Touil H, Bouzaiene M. Une etiologie rare d'une ulceration palatine: la sialometaplasie necrosante. J Tunis ORL Chir Cervico-Faciale. 2013;30:70-71.

[9] Kaplan I, Alterman M, Kleinman S, Reiser V, Shuster A, Dagan Y, et al. The clinical, histologic, and treatment spectrum in necrotizing sialometaplasia. Oral Surg Oral Med Oral Pathol Oral Radiol. 2012; 114(5) :577-585.

[10] Guenane Y, Djilani A, Saari B. Sialométaplasie nécrosante: à propos d'un cas. Médecine Buccale Chir Buccale. 2014; 20(4): 263-267.

[11] Leena Ylikontiola, Maria Siponen, Tuula Salo, George K.B. Sándor. Sialometaplasia of the Soft Palate in a 2-Year-Old Girl. J Can Dent Assoc. 2007;73(4): 333-6. 